\title{
The Value and Impact of a Brief Study Abroad Experience on Historically Black College and University (HBCU) Counseling Students' Learning
}

\author{
Michael Brooks ${ }^{1}$, Jeff D. Wolfgang ${ }^{1}$, Shirlene Smith ${ }^{1}$, Yasmin Gay ${ }^{1,2} \&$ Yvonne Ward $^{1}$ \\ ${ }^{1}$ College of Education, North Carolina Agricultural and Technical State University, Greensboro, NC, United States \\ ${ }^{2}$ School of Medicine, Wake Forest University, Winston-Salem, NC, United States \\ Correspondence: Michael Brooks, College of Education, North Carolina A\&T State University, 1601 E. Market St., \\ Greensboro, NC, 27411, United States.
}

Received: September 6, 2019

doi:10.11114/ijsss.v7i6.4506

\author{
Accepted: September 30, $2019 \quad$ Available online: October 17, 2019 \\ URL: https://doi.org/10.11114/ijsss.v7i6.4506
}

\begin{abstract}
This was an exploratory study that sought to understand the experiences and benefits of counseling graduate students from a Historically Black College and University (HBCU). These doctoral and master's students engaged in a brief study abroad experience centered on learning about the historical aspects of counseling in two European locations (Vienna, Austria and London, England). The qualitative methodology used in this study was the naturalist inquiry method, which emphasizes the importance of here-and-now experiences, critical reflections, and dialogues. With a sample size of eight, these tools allowed for a humanistic portrayal while being flexible enough for a creative synthesis in terms of understanding the process as the data portrayed it. Despite the limitations of having a pre-set program type, limited financial resources, and limited sample: this study discovered four themes in the experiences of the counseling students: (1) Self-fulfillment (believing in my own ability to grow), (2) Engaging in painless deep learning, (3) Values and impact, and (4) Study abroad is a "Big Deal,".
\end{abstract}

Keywords: HBCUs, naturalistic inquiry, study abroad, counseling

\section{Introduction}

In the context of increasing calls for global citizenship in the twenty-first century, studying abroad has uniquely contributed to the development of students' overall intercultural understandings (Twombly, Salisbury, Tumanut, \& Klute, 2012). The experience can provide students with opportunities for personal growth, global learning, enhanced awareness of ethical complexity of the counseling field, and changes in their worldview (Luo \& Jamieson-Drake, 2015; Smith, McAuliffe, \& Rippard, 2014; Tarrant, Rubin, \& Stoner, 2014). Historically Black Colleges and Universities (HBCUs) have been slow in taking bold steps to make study abroad a requirement; however, this notion is changing (Covington, 2017).

Historically Black Colleges and Universities are often able to tap into their students' distinct potentials, which may have been unrecognized by majority universities. Moreover, the desire to broaden students' horizons is experienced when a Historically Black Colleges and Universities (counseling) graduate student travels abroad. Previous research has identified the value of study abroad and how Historically Black Colleges and University students can benefit from global learning experiences (Covington, 2017; Smith-Augustine, Dowden, Wiggins, \& Hall, 2014; Tarrant, et al., 2013). Little published research, however, exists on how learning can be enhanced from Historically Black Colleges and University students engaging in study abroad experiences. Therefore, the principal investigators here sought to understand the likely impact of studying abroad on graduate students' learning and professional outlook. In the study, student participants took part in a study abroad program in Vienna (Austria) and London (England) designed to explore the founders of counseling/psychology theory: Freud, Adler, Jung, and Frankl (Taylor, 2009). While the overall intent of the study was to examine the likely benefits of Historically Black Colleges and Universities study abroad programs for counselor education purposes, it is important to consider some of the hurdles and challenges to such initiatives. The following descriptions will elaborate on the challenges faced by Historically Black Colleges and University institutions and their students when considering study abroad opportunities. 


\subsection{HBCUs Study Abroad Challenges}

Perhaps one of the greatest barriers to involving Historically Black Colleges and University students in studying abroad is in opening the students' minds to the basic notion of leaving their home country to seek an experience in foreign lands (Brux \& Fry, 2009). Students of color, especially those of African descent, are still often first-generation college students, with few normally seeking graduate and advanced degrees (Covington, 2017). Some of the commonly known impediments to such students traveling elsewhere include the following.

- Family. Black parents and other family members are commonly apprehensive about their children/loved ones participating in study abroad programs. Brux and Fry (2009) found family disapproval to be a major factor affecting Historically Black Colleges and University students engaging in such experiences, with this often based on a generalized fear of the unknown. Students engaging in study abroad are often the first in their families to travel abroad. Just as education encourages a certain progression of thought, it also leads to curiosities, but not all family members will share this view, and they may actively resist it.

- Racism. Students of color have reported suspicious feelings (mistrust, doubt, and fear) of racism experienced while abroad or within the traveling group (Perdreau, 2002). Racism is often misunderstood as a phenomenon, it has been characterized as being specific to the United States (Salem \& Thompson, 2016). However, the reality is racism is a worldwide reality (Kenqu, 2019). When students of color experience racism abroad, it is often unexpected and can have a compounding effect on what is regularly experienced domestically.

- Funding. Those students who are not on financial assistance typically work full-time jobs to pay for school (Akomolafe, 2000). Studies abroad are not cheap or always affordable. The majority of Historically Black Colleges and University students attend college/graduate school with the help of financial aid and scholarships. Historically Black Colleges and Universities recognize these financial constraints yet the institutions are only able to assist on a minimal and inconsistent basis. If students do not have funds, they are restricted from participating, thus, limiting their opportunities for global experiences and professional growth.

- Institutions. Institutional obstacles also may exist, as a great number of Historically Black Colleges and Universities do not offer a comprehensive global experience (West-Olatunji, Goodman, Mehta, \& Templeton, 2011). A comprehensive global program includes short-term (1-21 days) and long-term (21 or more) experiences; abroad degree programs (partial and full degree curriculums), as well as faculty exchanges. It is rare for Historically Black Colleges and Universities to have the resources to offer and maintain such a range of opportunities to their students and faculty.

\subsection{HBCUs Counseling Students' Global Education}

There have been other studies conducted which focus on the cross cultural experiences with an emphasis on experiential matters. The scholarship objectives of this study are different in that the experiences of Historically Black Colleges and Universities counseling students while studying abroad and their professional outlook are being emphasized. These previous inquiries have helped to establish a basis for the current investigation.

An earlier investigation of counseling students' of color engaging in abroad experiences was done when Day-Vines, Barker, and Exum (1998) investigated the impact of a study abroad program in Ghana. Eighteen (18) African American undergraduate students undertook the experience and submitted essays to be analyzed. The major themes emerging in the essays about the experience included: (a) awareness of stereotypes, distortions, and omissions related to education in Africa and substituting more accurate representations; (b) experiencing emotional links to their slave history; (c) examining American cultural values more critically and analytically; (d) experiencing growth in terms of ethnic identity, racial identity, and intercultural sensitivity; and (e) experiencing enhanced achievement and motivation. Although some of these benefits conceivably accrue from all study abroad students, some are clearly unique to African American students. The primary difference between the Day-Vines et al (1998) study and the current study is the emphasis on cross cultural experiences versus more scholarly/career goals.

Another study abroad experience involving tribal college students was conducted by Calhoon, Wildcat, Annett, Pierotti, and Griswold (2003). Haskell Indian Nation students in the US interacted with Altaian students Siberia in activities designed to develop mentored learning experiences and connectedness with the greater indigenous communities. The researchers were seeking to affirm if traditional study abroad contrasts with "many American Indian values (e.g., developing exchanges that equally privilege all shareholders)" (p. 46). They also argued that pan-national alliances can be developed to serve mutual needs and that well-designed programs, such as the one which brought Native American students to study abroad in Southwestern Siberia, can benefit both American Indian students and the natives of other countries. Similar to the Day-Vines, et al. (1998) study, the study within this manuscript differs with regard to the sampled participants and emphasizes cross cultural experiences. 
One of the few studies investigating Historically Black Colleges and Universities counseling students, who studied abroad, was conducted by Smith-Augustine, et al. (2014). This research team explored the experiences of five African American master's level counseling students who participated in a 3-week international immersion to Belize. In addition to cultural lectures, tours, and demonstrations, the participants completed community service learning at local agencies. Four cultural awareness themes (discrimination and prejudice; cultural pride and appreciation; cultural sensitivity, and overall self-awareness) emerged from the data which supported the use of immersion as a pedagogical tool to expand students' cultural and self-awareness (Smith-Augustine, et. al. 2014).

\subsection{Exploring Benefits and Naturalistic Inquiry Design}

Although, the current study is investigated from the perspective of the Historically Black Colleges and Universities counseling student, and is qualitative in nature, there are some differences. Not only does the published study extend the participant group by including $\mathrm{PhD}$ (doctoral) students, it also utilizes a naturalistic inquiry method; focusing on the new knowledge acquired as a result of study abroad. Moreover though, it helps to make the case that Historically Black Colleges and Universities provide a serious opportunity for its students to gain a pivotal experience in their professional development. Unfortunately, as the authors mentioned earlier in the manuscript previous research has stated the need for study abroad and how Historically Black Colleges and University students benefit from global learning experiences (Covington, 2017; Smith-Augustine et al., 2014; Tarrant, et al., 2013). Little published research exists on how learning can be enhanced from Historically Black Colleges and University students engaging in study abroad, it is hoped this study will directly help address this need.

\section{Method}

The qualitative methodology used in this study was the naturalist inquiry method (Patton, 2015). This methodology allowed the use of context to extrapolate meaning and value from student experiences (Beuving \& De Vries, 2015). The researchers used 'empathic neutrality' and design flexibility to ensure credibility, trustworthiness, and authenticity while actively tracking and responding to participants throughout the study abroad experience (Patton, 2015).

\subsection{Participants Characteristics}

Participants in this study were 5 African American, two (2) White, and 1 Asian counseling and counselor education graduate student and a group of all women $(\mathrm{n}=8)$. Students were recruited using the university counseling department email listserv, blackboard announcements, email listings, word of mouth, and interest meetings. Five of the students were at the doctoral level and 3 were at the master's level. The students' subspecialty areas ranged from clinical mental health, school, and rehabilitation counseling. The majority $(n=8)$ of the students were full-time and ranged from 25-56 years of age. One participant was a part-time returning adult student. Of the 8 students, 4 had previously traveled abroad. However, three (3) of 8 had never been on an airplane, nor traveled outside of the United States. One of which was the first in their entire family to board an airplane, and travel anywhere - let alone abroad. In a period of 9 days, these students traveled to three countries; and crossed an ocean. Two of the 8 students were very familiar with traveling abroad. Both these respective students were born and lived outside of the United States. Overall, students chose to participate in this study abroad program because of the opportunity to increase their depth of knowledge regarding counseling and some of the founding counseling theorist. In addition to the academic enhancement, the group itself had unique interactions based on their previous traveling exposure.

\subsection{Faculty Travelers/Facilitators}

There were two male faculty facilitators; one serving as the lead and other as an assistant. Both were experienced travelers; logging significant time in other countries and studying abroad. The main facilitator has traveled abroad since early childhood. It was during these early formative years he realized the benefits of the global experience. He has previously co-lead student program groups, attended trainings and workshops on study abroad, and has presented on study abroad at professional referred conferences. The assisting male facilitator, grew up with a transnational identity, having lived and spent significant time with people from around the globe.

The faculty travelers were primarily responsible for the design, coordination, advertising, and general oversight of the Study Abroad Program. Faculty members were required to seek university approval, soliciting donors to assist with cost, and hosting informational meetings for potential travelers. Prior to departing for Europe, the facilitators thought it would be a good idea to have pre-departure meetings. Six meeting were scheduled; the first was a year from the departure date, the remaining meetings were monthly during the remaining 5 months. The facilitators created topics based on brainstorming with one another and causal interactions with student travelers. The discussion meetings were all lead by the faculty facilitators and consisted of (1) international travel, fundraising, expectations, food, and free time options. 


\subsection{Study Abroad Program Details}

Students participated in a 9-day educational program tour to Vienna, Austria (4.5 days) and London, England (4.5 days). The program agenda and daily details were predetermined by a company specializing in short-term (14 days or less) study abroad experiences. option was determined as the best option for a counseling program that was relatively new to global education. The third-party company arranged for lodging, meals, discussion space, and air/ground transportation. The Vienna/London program had a clear emphasis on the works of Sigmund Freud, Alfred Adler, Carl Jung, Viktor Frankl, and Charles Darwin - all major contributors to the field of counseling.

The first leg of the air travel from the U.S. to Vienna lasted approximately 15 hours. Day two and three in Vienna, consisted of expert guided tours of local sites with significance to counseling, a welcome dinner consisting of traditional Austrian foods/dishes, and ended with a visit to the Viktor Frankl Institute. Unexpectedly, Viktor Frankl's widow, Eleonore Katharina Frankl was visiting the museum that very same day. This meeting was impactful on the students, as Ms. Frankl shared how meaningful it was to her that young people were still coming to learn about Viktor Frankl. Our final day in Austria, the group visited the Sigmund Freud museum, some of his living residences, and a local mental health teaching hospital.

The second leg of air travel on day five and six, we traveled from Vienna to London where we again toured local sites with an expert guide and took part in a traditional English meal. Day seven and eight was dedicated to studying counseling/psychology influential figures and sites. We visited a psychological hospital; one of the oldest and famous in Europe, the home of Sigmund/Anna Freud, and the Charles Darwin House. Being able to see Dr. Freud's personal artifacts, his famous couch where he provided treatment, and perusing his library was gratifying as students were able to see the items they've been reading about. Additionally, the Darwin House tour, enlightened students to the fact that Darwin was one of the first scientists to explore and write about human sociability and cooperation as a species. His volume, The Expression of the Emotions in Man and Animals (2006/1872), providing the foundation for counseling and mental health professions. The group left England and returned to the United States on day nine.

\subsection{Research Design and Procedures}

In a pre-departure meeting, the group agreed to using their study abroad experiences as a researched study. The faculty facilitators obtained approval from the university institutional review board (IRB) and the student members were informed that participation was voluntary and non-participation in the study would not affect their ability to travel with the group. As part of the requirements for participation, students were asked to submit daily journal entries where they responded to the following questions: 1. How has today's experience influenced your professional outlook? 2. What were your thoughts/feelings regarding today before, during and post experience? 3 . What did you learn today (related to counseling and counseling theory)? The rationale for the journal and journal questions were: (a) to gain an understanding of the impact of an intercultural experience on graduate students, (b) to reinforce subsequent missions by reiterating the importance of study abroad travel on the psycho-social and professional development of African-American graduate counseling students, (c) to increase student participation on study abroad programs, and (d) to determine the impact of the study abroad on the student's knowledge and awareness.

Each journal was read, themes were identified, coded, and categorized using Patton's (2015) criteria. Within this naturalistic inquiry framework, the researchers focused on the "erlebnis", the experience, interpretation, and the essence of the students while studying abroad (Kolb \& Kolb, 2005). Research explored through this lens of experiential learning (Kolb, 2015; Moon, 2004), emphasizes the importance of here-and-now experiences, critical reflections, and dialogues. Credibility and trustworthiness were maintained by: (a) utilizing multiple data (written daily journals and pictures/video/audio recordings), (b) investigator triangulation (multiple researchers in an investigation), and (c) performing member checks to gain respondent validation (Merriam \& Tisdell, 2016; Patton, 2015). In this systematic analysis, the researchers coded the data independently coming up with codes/quotes/themes as the first cycle (axial) coding (McLeod, 2011). Only those codes and thematic patterns where two or more researchers agreed were kept as relevant data. A double hermeneutic was created, forming a dialogic process of transforming the intersection of participant meaning (journals, pictures, and video) and the themes created by the researchers understanding of the experiences (Ginev, 2016). These tools allowed for a humanistic portrayal while being flexible enough for a creative synthesis in terms of understanding the process as the data portrays it.

\section{Findings and Discussion}

The analysis of data regarding the learning experiences of Historically Black Colleges and University students who engage in the study abroad encounter can be reduced to four themes: (1) Self-fulfillment, (2) Study abroad is a "Big Deal," (3) Engaging in painless deep learning, and (4) Values and impact. Embedded within each of these themes are corresponding barriers to Historically Black Colleges and University students and study abroad. In elaborating, a frequently noted barrier to self-fulfillment were Jonah Complex in nature (Hartman \& Zimberoff, 2008). Some of the 
students noted apprehension to sacrifice comfort for personal growth. A barrier to the "Big Deal" theme were thoughts and feelings associated with homesickness and leaving the country (for many, for the first time). Many of the student travelers expressed trepidation in being away from "home" in a new country, where there was no familiarity with the language, customs and culture. Also, some of the travelers, being abroad and participating in the study abroad short program format (10-days), felt it was not academically rigorous enough. Lastly, some of the students spoke about being treated in a disrespectful way; possibly due to them being Black. This is framed by a participant stating, "We noticed when walking in people starred at us...I know the "look" ... we watched how the waitress sat another couple who came in after us...". Several researchers have noted similar study abroad experiences of their Black students (Goldoni, 2017; Willis, 2015).

\subsection{Self-Fulfillment (Believing in My Own Ability to Grow)}

Throughout the data analysis, there were illustrative examples of self-actualization. Student travelers, as a result of their engagement in the study abroad experiences spoke of a developing confidence (esteem) and belonging (friendship). "I am so excited and feel like this is going to be a life changing experience. I've never done anything like this before, but I am ready." "This is a transitioning period for me where I am facing a fear...doing something different, new and life changing. I am still amazed by all of this..."

There were aspects (different types food, new languages, unfamiliar topography/architecture, etc.) which confronted participants to address as a result of being abroad; students spoke about their new self-awareness. This process is represented in a student's reflection, "I'm still thinking about the interplay between power, privilege, and race. That's probably the most lasting gift this trip has given me, a glimmer of insight into some of the experiences of others."

The above findings are consistent with research (Smith-Augustine et al., 2014) regarding the benefits of study abroad. The life changing opportunities along with the chance to take one's learning to an international level are a few major listed advantages. However, the findings from this theme also speak to some other potential issues faced by Black students studying abroad. According to the Institute on International Education (2017), only 5\% of those in the U.S. who travel internationally for college are African-American. This particular statistic is especially startling since there are more Blacks in higher education than ever before (IIE, 2017). The implications of this finding could lead to Black people losing global perspective. International travel creates cosmopolitanism, the ideology that all human beings belong to a single community (Connell, 2011). The phenomenon of Blacks traveling abroad has wide advantages.

\subsection{Deeper Learning}

The learning experiences in this particular study abroad program were unique in that dialogue regarding Black issues from Black perspectives was common. The student travelers also discussed how studying abroad added depth and breadth to their general counseling knowledge. Many of the student travelers initially felt secure in their grasp on counseling theory and philosophy. However, these same students were pleasantly impressed with how their current understanding could be enhanced and amplified.

- "I feel like I have a better understanding...I feel inspired to continue to learn. This was transformative in so many ways...I don' t think experiential learning can be topped by any other form of learning."

- "I get a bit emotional thinking of how proud I am making my family, my friends, and myself just by being here altogether. I've observed a lot... increased my passion and endurance for the (counseling) profession in a deeper sense of appreciation...”

- "This experience has broadened my experience about the world... and I am so glad I chose to attend. I am having a great time and learning a lot about the field of counseling...”

- "I am a visual learner, so being able to experience the books in physical form helped with the understanding $\cdots$ [this experience] has helped me look at life and difficult situations in a different light.”

These quotes exemplify how the experiential nature of study abroad has led to these expressions of gratification and appreciation. As evidence by participants, the above quotes were consistent with study abroad literature (Costello, 2015).

\subsection{Importance and Value}

Report Because many of the participants were first time travelers and new to global education, we anticipated major revelations regarding the importance and value of being abroad. The literature highlights cultural expansion, and the obtainment of invaluable life experiences as a few justifications for global studies. Specific to people of color, studying abroad offers opportunities to validate or invalidate previously conceived notions - some of which were based in stereotype. The students had similar thoughts.

- $\quad$ "I highly valued my study abroad experience. Being that I've never been out of the country, the study abroad 
experience provided me able to learn and explore new elements, which was priceless! My study abroad experience was transformational. My study abroad experience changed the way I approach situations from a cultural competence perspective because I can now relate to how individuals who come to the US feel as they experience a different cultural dynamic, especially within a counseling setting. This further validated the notion that integrating one's cultural aspects is essential. I also have more empathy for their experience and being. Also, I have become more interested in travel and understanding how such can further inform and shape my professional and personal development as a counselor and counselor educator."

- "Traveling with a diverse group in terms of age, education level, race/ethnicity, and socioeconomic status has allowed me an opportunity to not only see it through my own sociocultural lens, but those of my traveling companions as well. This adds value to my daily life as a world citizen because I am more aware of the ways my views are similar and different from those with whom I work and interact. This increased awareness translates into stronger communication and community building skills."

- "The study abroad experience has made me appreciate my country and overall American culture more. At the same time, it renewed my sense that we as a group do have shared values and can continue to make progress in a time of cultural strife.”

- "To this day, I still think about this trip several times a week, since we returned. I often look through the pictures and have shared stories of my experience on numerous occasions. The study abroad experience resulted in creating a lasting and deep impact and inspired me to remain a lifelong learner."

- "I would say that the impact is still very much felt after a year. Beyond the academic learning aspect this trip was served as an opportunity to learn many other great lessons such as adjusting to new spaces, adapting to new food, cuisine, mannerisms, time zones, weather, and overall culture."

In the traditional classroom learning environments, there are several controlled factors as well as few opportunities for students to be influenced by their surroundings. Many concepts are discussed, however, few of these topics are experienced. Students who travelled and participated in this study spoke of being able to go beyond their learning expectations. One student reflected on the difference between discussing a topic and being able to feel it. "Today I was really able to immerse in the culture."

Such a critical reflection is a core aspect of transformative learning (Brooks, Alston, Townsend, \& Bryan, 2016). These reflections incorporate perceptions of students and the persona of students to better cultivate genuine relationships that encompass a drive towards success and progression. Even though learning depends on the nature of dialogue between professor, student, and peer relationships, transformative learning is stimulated by experiential instances and events that challenge the habitual expectations about one's self and surrounding entities (Cranton, 2006)..

\subsection{Study Abroad Experience Is/Was a "Big Deal"}

The student travelers represented a cross section of encounters and influences; ranging from travelers who had never boarded a plane to those who have lived abroad for years. Their reflections revealed how impactful expanding their personal boundaries has changed them and the potential for future work, "What a huge leap of faith to travel... Never thought I would be doing this at all."

The idea of studying abroad seemed daunting at first to several of the travelers. Students spoke of feelings of anxiety as they were preparing to leave their families and board airplanes; all to engage in transcontinental learning. Soon however, they discovered they could trust their new environment. Overcoming this initial difficulty develops maturity and the ability to handle new situations (Jordi, 2010). The whole experience of going abroad for a period of time lead to boost in confidence as students discovered new coping and thriving abilities.

- " $\quad$ Traveling abroad put a great deal into perspective for me in terms of so much that is taken for granted."

- "My experience traveling abroad has taught me so much about myself and what I desire in life. I want to live life to the fullest and I cannot do such if I am fearful of the unknown."

Not all institutions have the ability to develop identity-specific programs and may have programs in varying parts of the world. However, when intentionally and thoughtfully designed, programs can still make heritage seeking and racial identity development a priority for student participants regardless of racial or ethnic background. Being a part of the study abroad allowed the students to further discover their own identities. By removing them from their comfort zones they discovered new foods, cultures, places, and people (just to name a few examples). Their interests were piqued that could have never happened in their hometowns. Although there might be some nervousness around being in new and different surroundings, there is also character development in being abroad (Perdreau, 2002). "I feel like I am experiencing another surreal moment.".) 


\subsection{Limitations of the Study}

Although this study was exploratory, there were several limitations: the program type, financial resources, limited sample, and limited sample size. The first limitation was the program itself was pre-arranged and could not be specifically altered to the needs of the students. The program would have been more impactful if it were designed with the Historically Black Colleges and Universities graduate counseling students in mind (lodging options, length of time in each country, and food options). The students also had a strong desire to speak with active counselors or people who worked as counseling professionals.

Financial resources were also a limitation of the study. As listed earlier, having the ability to pay for global experiences is a challenge for undergraduate (Redden, 2018) students. Such costs are magnified when these students are in graduate school. Historically Black Colleges and Universities graduate students are often supporting households, gainfully employed, and still need the assistance of Federal financial aid. Many of the participants of this study had no scholarships or stipends and had to pay the entire expense completely out of pocket. Even those who were fortunate to secure partial support, it was still difficult at times to cover the remaining balance. Finally, the study included a small sample of counseling students of which there were no males in the sample. Therefore, although the results were informative as an exploratory study, the findings may be limited by gender (female experiences).

\section{Discussion}

After Tools enhancing experiential learning are critically important in ensuring counselors in training are able to meet the cultural competency standards (Arthur \& Achenbach, 2002). In 2015/2016, less than 29\% of students who studied abroad were non-white (Institute of International Education, 2017). Counselor education students who attend minority serving institutions, if provided the opportunity, can achieve maximum knowledge gains by participating in study abroad. It is imperative that counselor faculty (and respective programs) affirm global citizenship (Okorodudu, 2006) as a necessity and create opportunities for such groups.

Because this study is new and introductory in subject matter, future counselor education scholarship could extend this work by investigating differences between counseling programs able to fully participate (short/long term options, professor swap, degrees being offered completed abroad) in study abroad to those that are not. Empirical data could be a useful tool in helping programs in establishing and maintaining international efforts. Data could also assist programs in possible standardizing of internationalization (American Counseling Association, 2019). Counseling has proven to be quite "global;" possessing local, national, and international considerations.

In sum, from the broadest perspective, people of color, and specifically Black people not traveling abroad is extremely problematic. International experiences for Americans of color are one of the last areas to be explored let alone integrated. Although more students of color are in higher education - for example - (Institute of International Education, 2017) only 6\% of Americans who study abroad are Black. Typically, when racial disparities are discussed, the conversation is limited to (un)employment, home ownership, access to health care, and public schools' performance; going abroad is the spillover of problems in American society. The development and implementation of this project was an attempt to increase efforts in addressing this complication.

\section{Acknowledgements}

The first and second authors would like to acknowledge the support of the Center for European Studies at the University of North Carolina at Chapel Hill in the form of international travel grants.

\section{References}

American Counseling Association. (2019). Interest Networks: ACA international counseling interest network. [Online forum]. Retrieved from: https://www.counseling.org/aca-community/aca-connect/interest-networks\#International

Akomolafe, O. (2000). Africanizing HBCUs: Problems and prospects of international education in historically Black institutions. African Issues, 28(1-2), 103-107. https://doi.org/10.2307/1167069

Arthur, N., \& Achenbach, K. (2002). Developing multicultural competencies through experiential learning. Counselor Education \& Supervision, 42, 2-14. https://doi.org/10.1002/j.1556-6978.2002.tb01299.x

Beuving, J., \& de Vries, G. (2015). Doing qualitative research: The craft of naturalistic inquiry. Amsterdam, Netherlands: Amsterdam University Press. https://doi.org/10.2307/j.ctt130h8g7

Brux, J. M., \& Fry, B. (2009). Multicultural students in study abroad: Their interests, their issues, and their constraints. Journal of Studies in International Education, 14(5), 508-527. https://doi.org/10.1177/1028315309342486

Brooks, M., Alston, G., Townsend, C., \& Bryan, M. (2017). Creating a healthy classroom environment in multicultural counseling courses. Journal of Human Services: Training, Research, and Practice, 2(1), 1-24. Retrieved from 
https://scholarworks.sfasu.edu/jhstrp/vol2/iss1/3/

Calhoon, J. A., Wildcat, D., Annett, C., Pierotti, R., \& Griswold, W. (2003). Creating meaningful study abroad programs for American Indian postsecondary students. Journal of American Indian Education, 42(1), 46-57.

Connell, C. (2011). Weaving service into study abroad. International Educator, 20(3), 66-78.

Costello, J. (2015). Students of study abroad: Reflections upon return. Journal of International Students, 5(1), 50-59.

Covington, M. (2017). If not us then who? Exploring the role of HBCUs in increasing Black student engagement in study abroad. College Student Affairs Leadership, 4(1). Retrieved from https://scholarworks.gvsu.edu/csal/vol4/iss1/5

Cranton, P. (2006). Fostering authentic relationships in the transformative classroom. New Directions for Adult and Continuing Education, 2006(109), 5-13. https://doi.org/10.1002/ace.203

Day-Vines, N., Barker, J. M., \& Exum, H. A. (1998). Impact of diasporic travel on ethnic identity development of African American college students. College Student Journal, 32(3), 463-471.

Ginev, D. (2016). Hermeneutic realism: Reality within scientific inquiry. SG, Switzerland: Springer International Publishing. https://doi.org/10.1007/978-3-319-39289-9

Goldoni, F. (2017). Race, ethnicity, class and identity: Implications for study abroad. Journal of Language, Identity \& Education, 16(5), 328-341. https://doi.org/10.1080/15348458.2017.1350922

Hartman, D., \& Zimberoff, D. (2008). Higher stages of human development. Journal of Heart-Centered Therapies, 11(2), 3-95.

Institute of International Education. (2017). Profile of U.S. study abroad students, 2004/05-2015-16. Open Doors Report on International Educational Exchange. Retrieved from http://www.iee.org/opendoors

Jordi, R. (2010). Reframing the concept of reflection: Consciousness, experiential learning, and reflective learning practices. Adult Education Quarterly, 61(2), 181-197. https://doi.org/10.1177/0741713610380439

Kenqu, Y. (2019). Black south African artists in conversation: Nongqawuse, 'the bellow of the bulls' and other travelling tropes in zakes mda's the heart of redness. English in Africa, 46(1), 57-78. https://doi.org/10.4314/eia.v46i1.3

Kolb, A., \& Kolb, D. (2005) Learning styles and learning spaces: Enhancing experiential learning in higher education. Academy of Management Learning \& Education 4(2), 193-212. https://doi.org/10.5465/amle.2005.17268566

Kolb, D. A. (2015). Experiential learning: Experience as the source of learning and development (2nd ed.). Upper Saddle River, NJ: Pearson Education, Inc.

Luo, J., \& Jamieson-Drake, D. (2015). Predictors of study abroad intent, participation, and college outcomes. Research in Higher Education, 56(1), 29-56. https://doi.org/10.1007/s11162-014-9338-7

McLeod, J. (2011). Qualitative research in counseling and psychotherapy (2nd ed.). Thousand Oaks, CA: SAGE Publications, Inc.

Merriam, S. B., \& Tisdell, E. J. (2016). Qualitative research: A guide to design and implementation. (4 ${ }^{\text {th }}$ ed.). San Francisco, CA: Wiley \& Sons.

Moon, J. (2004). A handbook of reflective and experiential learning: Theory and practice. New York, NY: RoutledgeFalmer.

Okorodudu, R. (2006). Global citizenship: Implications for guidance and counselling innovations in developing nations. International Journal for the Advancement of Counselling, 28(2), 107-120. https://doi.org/10.1007/s10447-005-9002-1

Patton, M. Q. (2015). Qualitative research \& evaluation methods: Integrating theory and practice (4th ed.). Thousand Oaks, CA: SAGE Publications, Inc.

Perdreau, C. (2002). Study abroad: A 21st century perspective: Building diversity into education abroad programs. Retrieved from http://www.aifsfoundation.org/perdreau.htm

Redden, E. (2018). HBCU Students Abroad. Retrieved from https://www.insidehighered.com/news/2018/09/11/hbcus-seek-grow-study-abroad-participation

Salem, S., \& Thompson, V. (2016). Old racisms, new masks: On the continuing discontinuities of racism and the erasure of race in European contexts. nineteen sixty-nine: an ethnic studies journal, 3(1). Retrieved from https://escholarship.org/uc/item/98p8q169

Smith, J. E., McAuliffe, G., \& Rippard, K. S. (2014). Counseling students' transformative learning through a study abroad 
curriculum. Counselor Education and Supervision, 53(4), 306-319. https://doi.org/10.1002/j.1556-6978.2014.00065.x

Smith-Augustine, S., Dowden, A., Wiggins, A., \& Hall, L. (2014). International immersion in Belize: Fostering counseling students' cultural self-awareness. International Journal for the Advancement of Counselling, 36(4), 468-484. https://doi.org/10.1007/s10447-014-9219-y

Tarrant, M. A., Rubin, D. L., \& Stoner, L. (2014). The added value of study abroad: Fostering a global citizenry. Journal of Studies in International Education, 18(2), 141-161. https://doi.org/10.1177/1028315313497589

Taylor, E. (2009). The mystery of personality: A history of psychodynamic theories. New York, NY: Springer Science Business Media, LLC. https://doi.org/10.1007/978-0-387-98104-8

Twombly, S. B., Salisbury, M. H., Tumanut, S. D., \& Klute, P. (2012). Study abroad in a new global century: Renewing the promise, refining the purpose (Vol. 38). Hoboken, NJ: Wiley Periodical, Inc. https://doi.org/10.1002/aehe.v38.4

West-Olatunji, C., Goodman, R. D., Mehta, S., \& Templeton, L. (2011). Creating Cultural Competence: An Outreach Immersion Experience in Southern Africa. International Journal for the Advancement of Counselling, 33(4), 335-346. https://doi.org/10.1007/s10447-011-9138-0

Willis, T. Y. (2015). "And still we rise...”: Microaggressions and intersectionality in the study abroad experiences of Black women. Frontiers: The Interdisciplinary Journal of Study Abroad, 26, 209-230.

\section{Copyrights}

Copyright for this article is retained by the author(s), with first publication rights granted to the journal.

This is an open-access article distributed under the terms and conditions of the Creative Commons Attribution license which permits unrestricted use, distribution, and reproduction in any medium, provided the original work is properly cited. 